\title{
Profile of childhood leprosy in a tertiary care centre in an endemic state of India
}

\author{
Krupasindhu Pradhan, Dilip Kumar Sa ${ }^{2, *}$ \\ ${ }^{\mathbf{1}}$ Assistant Professor, ${ }^{\mathbf{2}}$ Associate Professor, Dept. of Dermatology, ${ }^{\mathbf{1}}$ Government Medical College, Balangir, Odisha, ${ }^{2}$ Late Shri \\ Lakhi Ram Agrawal Memorial Government Medical College, Raigarh, Chhattisgarh, India
}

*Corresponding Author:

Email: dr.dilip.kmc@gmail.com

\begin{abstract}
Introduction: Child cases of leprosy indicate early and continued transmission of infection and also serve as an epidemiological indicator of disease burden. Childhood leprosy may progress to disabilities with serious psychosocial impact on child and family. Materials and Methods: A cross-sectional study was undertaken in a tertiary care centre over a period of one and half year. Patients with age less than 14 years, having one of the cardinal signs of leprosy and giving consent for the study were included in the study. Detailed history taking, clinical examination and slit skin smear was performed and data were recorded in a predesigned case record form. Data were analysed statistically.

Results: 32 of 581 cases $(5.5 \%)$ of leprosy were children less than 14 years of age. Most common age group was 11 to 14 years. Male to female ratio was 2.5:1. Upper extremity was the most common site of lesions (46.87\%). BT was the most common form (65.62\%). PB cases (68.75\%) were more common than MB. Nerve thickening was found in $87.5 \%$ cases, lepra reactions in $15.62 \%$ cases, disabilities in $12.5 \%$ cases and slit skin smear positivity in $25 \%$ cases. BCG scar was noted in $65.62 \%$ cases and history of contacts in $40.62 \%$ cases.

Conclusion: Early diagnosis and treatment of child cases is necessary to reduce transmission of disease. High incidence of lepra reaction and disabilities in children in our study indicate prompt treatment of lepra reaction.
\end{abstract}

Keywords: Childhood, Leprosy, Lepra reaction, Nerve thickening, Disability.

\section{Introduction}

Leprosy is now considered eliminated globally; its prevalence being 0.25 per 10,000 population (at the end of 2017). ${ }^{1}$ India achieved the goal of leprosy elimination in $2005 .^{2}$ Thecurrent prevalence rate in India is 0.66 per 10,000 population. ${ }^{3}$ However, prevalence rate of more than 1 per10,000 population was recorded in states like Chhattisgarh, Bihar, Odisha \& Goa and union territories like Lakshadweep, Dadra \& Nagar Haveli and Chandigarh as on March,2017. ${ }^{3}$ Child rate of leprosy is defined as the percentage of children among all newly detected cases during a reporting year. In India, a total of 11792 child cases were recorded indicating Child Case rate of $8.7 \%$ during reporting year 2016-17. ${ }^{3}$ Proportion of child cases was more than $10 \%$ of new cases detected in 10 states/union territories. ${ }^{3}$ Child cases indicate early and continued transmission of infection in community. This is also an important epidemiological indicator and used in estimating drug requirement for the programme. Childhood leprosy is considered important because of its potential to cause progressive physical deformity and disability with serious psychosocial impact in child and family. Moreover, the disease in children is eminently responsive to treatment if detected in early stage. As the global target has been reached in all but a few countries, the most recent strategy indicates a shift from "elimination of leprosy as a public health problem" to reduction of the disease burden, measured as reduction in grade-2 disabilities (G2D) among new cases and new cases in children. ${ }^{1}$

Though there are a number of Indian studies on childhood leprosy, there are only few studies from an endemic state like Chhattisgarh (prevalence rate being 2.52 per 10,000 population as on March, 2017), especially during the post-elimination era. ${ }^{3}$ Hence, we aimed to perform a cross-sectional study on childhood leprosy among patients attending a tertiary care centre in Chhattisgarh (India).

\section{Materials and Methods}

This study was conducted in department of dermatology of Late Shri Lakhiram Agrawal Memorial Govt. Medical College, Raigarh (Chhattisgarh) from January, 2017 to June, 2018. Patients with age less than 14 years, having at least two of the three cardinal signs of leprosy and giving consent for the study were included in the study. The cardinal signs of leprosy includes; hypopigmented or erythematous skin lesion(s) with definite loss/impairement of sensations, involvement of peripheral nerves as demonstrated by definite thickening with sensory impairement and skin smear positive for acid-fast bacilli. ${ }^{4}$ Indeterminate leprosy cases were excluded from the study. Detailed history taking and clinical examination was done. Socio-economic status of patient's family was classified as low, middle and upper class on the basis of modified BG Prasad scale. ${ }^{5}$ Slit skin smear was performed in all cases and skin biopsy was taken in few cases. Suspected family members and neighbours were also examined. The presence of BCG (Bacillus Calmette Guerin) scar was deemed as an indication of prior BCG vaccination. Data were collected in a standard case record form. Microsoft Office Excel 2007 was used for statistical analysis. 


\section{Observations}

Total number of new leprosy cases registered during the study period was 581 , of which 32 patients $(5.5 \%)$ were children less than 14 years. Among them 12 cases (37.5\%) belonged to age group 6 to 10 years and 20 cases $(62.5 \%)$ to age group 11 to 14 years. We did not get any patient below 5 years of age. 23 patients were male $(71.87 \%)$ and 9 were females $(28.12 \%)$. Thus the male to female ratio was 2.5:1. 17 cases $(53.12 \%)$ belonged to low socioeconomic class (SEC), 14 cases $(43.75 \%)$ to middle SEC and 1 case(3.12\%) to upper SEC. 23 cases $(71.87 \%)$ were from rural area and 9 $(28.12 \%)$ from urban area.

We found generalized distribution of lesions in 7 cases $(21.87 \%)$, lesions over upper extremities in 15 cases $(46.87 \%)$, over lower extremities in 8 cases $(25 \%)$, over face in 6 cases $(18.75 \%)$ and over trunk in 5 cases $(15.62 \%)$. No skin lesions were found in 3 cases $(9.37 \%)$ and they were classified as pure neuritic leprosy(PNL) because of nerve thickening and sensory impairement along the distribution of thickened nerve. The most common clinical diagnosis was borderline tuberculoid (BT) [Fig. 1] found in 21 cases $(65.62 \%)$, followed by lepromatous leprosy (LL) [Fig. 2] in 5 cases (15.62\%), borderline lepromatous (BL) in 2 cases $(6.25 \%)$ and borderline-borderline (BB) in 1 case $(3.12 \%)$. PNL was found in 3 cases $(9.37 \%)$. As per WHO classification, 22 cases $(68.75 \%)$ belonged to paucibacillary $(\mathrm{PB})$ and 10 cases $(31.25 \%)$ to multibacillary (MB) leprosy. Nerve thickening was noted in 28 cases $(87.5 \%)$. Lepra reaction was found in 5 cases $(15.62 \%)$; 3 cases $(9.37 \%)$ having type 1 reaction [Fig. 3] and 2cases (6.25\%) having type 2 reaction. Grade 2 disability was found in 4 cases $(12.5 \%)$ cases; 3 cases having upper limb disability (claw hands) [Fig. 4] and one having lower limb disability (foot drop). Slit skin smear (SSS) positivity was found in 8 cases (25\%). All the SSS positive cases were from BB, BL and LL poles. BCG vaccine scar was present in 21 cases $(65.62 \%)$ and absent in 11 cases $(34.37 \%)$.

Contact history in households and neighbours were present in 13 cases $(40.62 \%)$. Father was the index casein 5 cases $(38.46 \%$ ) [Fig. 5] followed by mother in 3 cases $(23.07 \%)$, brother in 2 cases $(15.38 \%)$ and cousin in 1 case $(7.69 \%)$, uncle in 1 case $(7.69 \%)$ and neighbour in 1 case $(7.69 \%)$. Among the contacts, 9(69.23\%) were having MB leprosy and 4 (30.76\%) having PB leprosy.

\section{Discussion}

A comparative analysis of various Indian studies on childhood leprosy including our study is depicted in [Table 1].

Child proportion in various Indian studies varied from $4.18 \%$ to $11.43 \% .^{6-10}$ In the present study child proportion was $5.5 \%$ which indicates a good number child cases even in the post-elimination era. Most of our patients were from rural area $(71.87 \%)$. The most common age group in our study was 11 to 14 years like many other Indian studies. ${ }^{6-10}$ This could be due to long incubation period of disease, delay in diagnosis, lack of awareness and more exposure to outside people as the child starts schooling. Like many other studies we also noticed a male preponderance and male comprised $71.87 \%$ of all cases. ${ }^{6-10}$ More number of male cases is attributed to their greater mobility and increased opportunity for contact and also to negligence of parents towards girls in certain communities. Leprosy is more common in people with low socioeconomic status because of overcrowding, lack of education, lack of personal hygiene, lack of ventilation etc. which in turn favours increased transmission of disease. Present study also found $53.12 \%$ and $43.75 \%$ cases in people with low and middle socioeconomic class respectively.

In our study skin lesions were distributed mostly on upper extremities (46.87\%) and lower extremities (25\%) followed by face and trunk. Generalized distribution was found in $21.87 \%$ cases. Distribution of skin lesions over exposed parts is a constant observation by other authors like Singal et al. and Dogra et al. ${ }^{9,10} \mathrm{We}$ noted PB in $68.75 \%$ cases and this is consistent with many other studies which observed $\mathrm{PB}$ to be more common compared to $\mathrm{MB} \cdot{ }^{6-8}$ However, Singal et al. and Dogra et al. found $\mathrm{MB}$ to be the dominant type. ${ }^{9,10} \mathrm{With}$ the increase in age $\mathrm{PB}$ cases may progress to $\mathrm{MB}$ and hence early intervention is important. Various studies found BT to be the commonest type of childhood leprosy; its prevalence ranging from $58.1 \%$ to $73 \% .^{6,7,9,10} \mathrm{We}$ also found BT to be the commonest form (65.62\%). However, we observed a higher prevalence of LL $(15.62 \%)$ in contrast to other studies which noted this form in only $1.6 \%$ to $4.9 \%$ cases. ${ }^{11-13}$ This suggests any hypopigmented macule or patch in a child in endemic area should raise suspicion of leprosy and needs a detailed examination.

Nerve involvement was found in $52.3 \%$ to $81.4 \%$ cases by various Indian authors. ${ }^{6,8-10} \mathrm{We}$ observed nerve thickening in a higher proportion of children (87.5\%). This higher incidence of nerve involvement emphasizes a meticulous examination of nerve in each visit. Dogra et al. found PNL in $3.4 \%$ cases. ${ }^{10}$ But we found this form in a higher proportion of children $(9.37 \%)$. We diagnosed PNL in patients with thickening of nerve and sensory impairement along the distribution of thickened nerve.

In children, incidence of reaction varies from $2.3 \%$ to $33.9 \% .^{6-10,14}$ We observed reactions in $15.62 \%$ cases. Type 1 reaction may result in nerve deficit and consequently disability. Reactions in leprosy needs prompt intervention to reduce progression to disabilities and deformities. Fortunately, incidence of lepra reaction in children is less compared to adults.

Deformities and disabilities in children are more distressing psychologically and socially. Children with disabilities become a burden to the society for life time. The operational manual of Global Leprosy Strategy 2016-2020 define different approaches for high and low endemic settings to improve early case finding and reduce the disability burden. The 3 principal targets for 
2020 are zero new childcases with G2D, < 1 per million population of new leprosy cases with G2D and zero countries with laws or legislation that allow discrimination against people with leprosy. ${ }^{1}$ A study on disabilities in children identified the following risk factors; increasing age, delay in accessing healthcare, multiple skin lesions, multibacillary disease, smear positivity, multiple nerve involvement and reaction at the time of presentation. ${ }^{15}$ Nerve thickening was the most significant of all these factors increasing the risk of disabilities by 6.13 times. ${ }^{15}$ We found disabilities in $12.5 \%$ cases while other studies found it between $3.1 \%$ to $16 \%{ }^{6-10}$ Upper limb deformities was more common compared to lower limb. This high percentage of disabilities in children emphasize the need for their prevention, early detection and management.

We got smear positivity in $25 \%$ cases. All of them belonged to $\mathrm{BB}, \mathrm{BL}$ and $\mathrm{LL}$ forms. Other studies found smear positivity in $9.9 \%$ to $28.8 \%$ cases. ${ }^{6-10}$
BCG scar was noted in $65.62 \%$ cases. Sahoo et al. noted BCG scars in $73.33 \%$ cases. ${ }^{16}$ This indicates BCG vaccination in infancy does not give any significant protection from leprosy.

Presence of household or neighbourhood contact of leprosy increases the risk of leprosy. The risk is higher if the index case in family is a MB case. Sahoo et al. and Jain et al. noticed highest attack rate when the index case was mother. ${ }^{16,17} \mathrm{We}$ found contact history in $40.6 \%$ cases which is consistent with Horo et al. but this finding was less in other studies. ${ }^{6-10}$ In our study father was the most common index case followed by mother. The household contacts were mostly MB cases $(69.23 \%)$. However, in $30.76 \%$ cases PB contact was the source of infection suggesting PB to be a potential source of infection too. Thus, a detailed contact history and screening of family members is important while dealing with a child with leprosy.

Table 1: Comparison of profiles of childhood leprosy in various Indian studies

\begin{tabular}{|c|c|c|c|c|c|c|}
\hline & $\begin{array}{c}\text { Mahajan } \\
\text { et } a l^{6}(2006)\end{array}$ & $\begin{array}{c}\text { Rao et } a l^{7} \\
(2009)\end{array}$ & $\begin{array}{c}\text { Horo et } a l^{8} \\
(2010)\end{array}$ & $\begin{array}{c}\text { Singal } \\
\text { et } a l^{9}(2011)\end{array}$ & $\begin{array}{c}\text { Dogra } e t \\
a l^{10}(2014)\end{array}$ & $\begin{array}{c}\text { Present } \\
\text { study }(2018)\end{array}$ \\
\hline Child rate $(\%)$ & 7.71 & 11.43 & 15 & 9.6 & 4.81 & 5.5 \\
\hline $\begin{array}{l}\text { Male to female } \\
\text { ratio }\end{array}$ & $2.3: 1$ & $2.5: 1$ & $1.25: 1$ & $2.3: 1$ & $3.9: 1$ & $2.5: 1$ \\
\hline $\begin{array}{l}\text { Commonest age } \\
\text { group (years) }\end{array}$ & $11-15$ & $11-15$ & $11-14$ & $11-14$ & $11-14$ & $11-14$ \\
\hline WHO type(\%) & PB (63) & $\mathrm{PB}(81.2)$ & $\mathrm{PB}(67)$ & $\mathrm{MB}(51.7)$ & $\mathrm{MB}(52.5)$ & $\mathrm{PB}(68.75)$ \\
\hline $\begin{array}{l}\text { Commonest } \\
\text { clinical form }(\%)\end{array}$ & BT(73) & ВТ(68.5) & $\mathrm{TT}(43.5)$ & BT(70.3) & BT(67.8) & ВT(65.62) \\
\hline $\begin{array}{l}\text { Nerve thickening } \\
(\%)\end{array}$ & 70 & NS & 52.3 & 70 & 81.4 & 87.5 \\
\hline $\begin{array}{l}\text { Slit Skin Smear } \\
\text { positivity }(\%)\end{array}$ & 28 & 25 & 9.9 & 19.8 & 28.8 & 25 \\
\hline $\begin{array}{l}\text { Lepra } \\
\text { Reactions }(\%)\end{array}$ & 2.3 & 6.24 & 4.6 & 18.6 & 33.9 & 15.62 \\
\hline $\begin{array}{l}\text { Grade } 2 \\
\text { disablities(\%) }\end{array}$ & 13 & 3.12 & 16 & 12.8 & 40.7 & 12.5 \\
\hline Contacts $(\%)$ & 29 & 18 & 43 & 14.5 & 25.4 & 40.62 \\
\hline
\end{tabular}

PB - Paucibacillary, MB - Multibacillary, BT - Borderline tuberculoid, TT - Tuberculoid leprosy, NS-Not specified

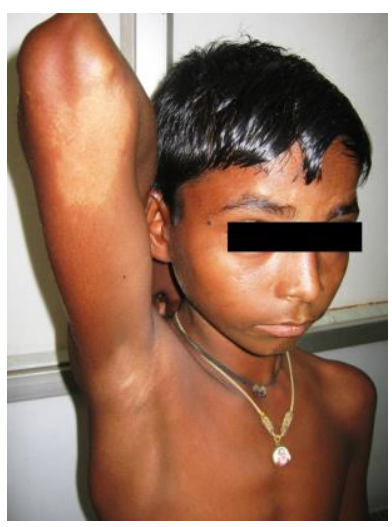

Fig. 1: A case of Borderline Tuberculoid (BT) leprosy

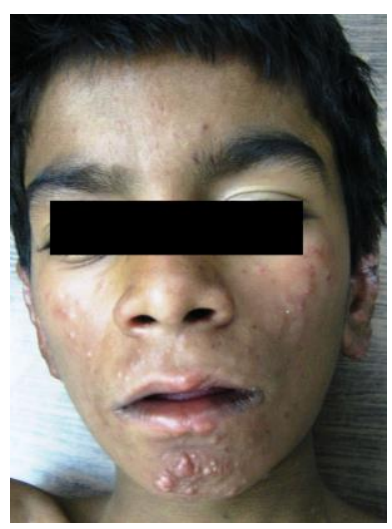

Fig. 2: A case of Lepromatous Leprosy (LL) 


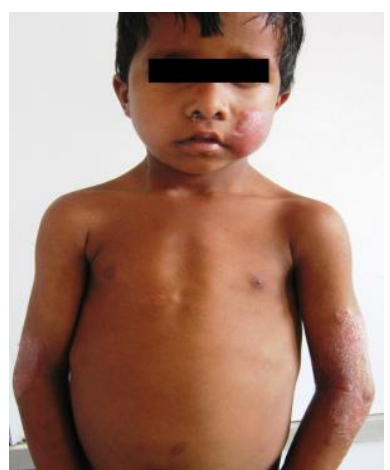

Fig. 3: A case of Borderline Tuberculoid leprosy with type 1 reaction

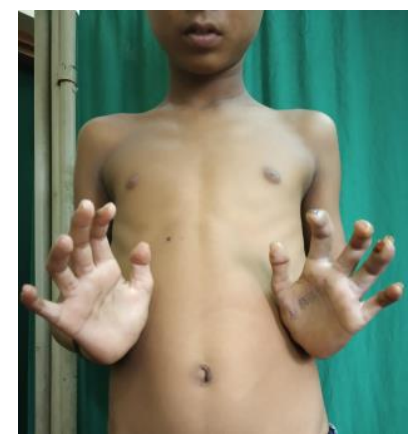

Fig. 4: Claw hands in a child with BT Leprosy

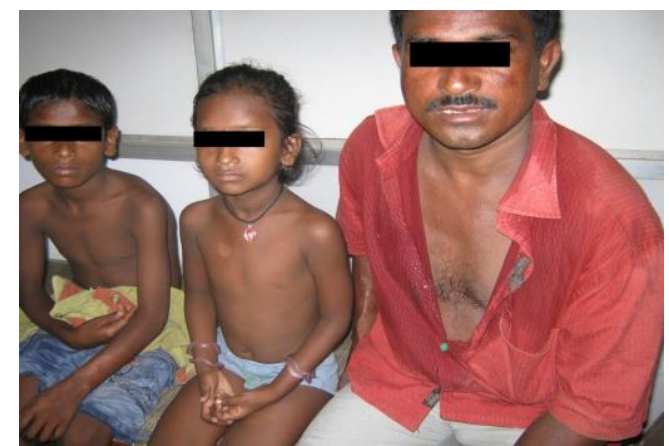

Fig. 5: Treated MB father with BT in both children

\section{Conclusion}

Leprosy continues to be an important health problem in children even in post elimination era, especially in endemic areas. Pattern of childhood leprosy in this part of India is almost similar to many others parts. Early cases which form a major risk group for transmission and progression to disabilities can easily be missed. Prompt treatment of lepra reaction is essential to reduce the progression to deformities and disabilities. Training of health workers and their close link with referral centres may further strengthen case detection and early management of childhood cases. Parental education and counselling, contact survey and school survey may also serve as important methods of early detection in endemic areas.
Conflict of interest: None declared.

\section{References}

1. World Health Organization. Global leprosy situation, weekly epidemiological record no. 3531 August 2018;93:445-56.

2. GPS Dhillon, "NLEP- current situation and strategy during $11^{\text {th }}$ plan period (2007-2012)". J Indian Med Assoc 2006;104:671-72.

3. NLEP Annual Report 2016 - 2017. Central Leprosy Division, Directorate General of Health Services, Ministry of Health and Family Welfare, Govt. of India.(www.nlep.nic.in)

4. Kumar B, Dogra S. Case definition and Clinical types. In: Kar HK, Kumar B (Eds). IAL Textbook of Leprosy. $1^{\text {st }}$ edn. Jaypee Brothers Medical Publishers (P) Ltd. 2010. pp 152-66.

5. Singh T, Sharma S, Nagesh S. Socio-economic status scales updated for 2017. Int J Res Med Sci 2017;5:326467.

6. Mahajan S, Sardana K, Bhushan P, Koranne RV, Mendiratta V. A study of leprosy in children, from a tertiary pediatric hospital in India. Lepr Rev 2006;77(2):160-62.

7. Rao AG. Study of leprosy in children. Indian J Lepr 2009;81:195-97.

8. Horo I, Rao PS, Nanda NK, Abraham S. Childhood leprosy: profiles from a leprosy referral hospital in West Bengal, India. Indian J Lepr 2010;82:33-7.

9. Singal A, Sonthalia S, Pandhi D. Childhood leprosy in a tertiary care hospital in Delhi, India: A retrospective appraisal in the post-elimination era. Lepr Rev 2011;82:259-69.

10. Dogra S, Narang T, Khullar G, Kumar R, Saikia UN. Childhood leprosy through the post elimination era: a retrospective analysis of epidemiological and clinical characteristic of disease over eleven years from a tertiary care hospital in North India. Lepr Rev 2014;85:296-310.

11. Vara N. Profile of new cases of childhood leprosy in a hospital setting. Indian J Lepr 2006;78:231-36.

12. Kumar B, Rani R, Kaur I. Childhood leprosy in Chandigarh: a clinico-histopathological correlation. Int J Lepr other Mycobact Dis 2000;68:330-31.

13. Burman DK, Rijall A, Agrawal S, Agarwalla A, Verma KK. Childhood leprosy in eastern Nepal: a hospital-based study. Indian J Lepr 2003;75:53-8.

14. Gupta R, Singal A, Pandhi D. Genital involvement \& type1 reaction in childhood leprosy. Lepr Rev 2005;76:253-57.

15. Kar BR, Job CK. Visible deformity in childhood leprosy: A 10-year study. Int J Lepr Other Mycobact Dis 2005;73(4):243-48.

16. Sahoo A, Singh PC, Patnaik S, Singh N. Incidence of leprosy in school children and their family members in Berhampur. Indian J Lepr 2002;74:137-43 .

17. Jain S, Reddy RG, Osmani SN, Lockwood DN, Suneetha S. Childhood leprosy in a urban clinic, Hyderabad, India : clinical presentation and the role of household contacts. Lepr Rev 2002;73:248-53.

How to cite this article: Pradhan K., Sa Dilip. Profile of childhood leprosy in a tertiary care centre in an endemic state of India. Indian J Clin Exp Dermatol 2018;4(4):278-81.

Funding: No funding sources. 